\title{
Reciprocal Interactions Between Bark Beetles and Wildfire in Subalpine Forests of the Greater Yellowstone Ecosystem
}

\author{
Authors \\ Martin Simard, Jake Griffin, Erin Powell, Suming Jin, Ken Raffa, Philip Townsend, Monica G. Turner, William \\ H. Romme, and Daniel B. Tinker
}




\title{
RECIPROCAL INTERACTIONS BETWEEN BARK BEETLES AND WILDFIRE IN SUBALPINE FORESTS OF THE GREATER YELLOWSTONE ECOSYSTEM
}

\author{
-

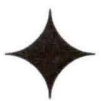 \\ Martin Simard, JAKe Griffin, ERIN Powell, Suming Jin, Ken RAFFA, Philip Townsend, \\ MONICA G. TURNER \ DEPARTMENT OF ZOOLOGY $\downarrow$ UNIVERSITY OF WISCONSIN \\ MADISON \\ WiLLIAM H. ROMME $\downarrow$ WARNER COLLEGE OF NATURAL RESOURCES \\ COLORADO STATE UNIVERSITY $\uparrow$ FT. COLLINS \\ DANIEL B. TINKER $\uparrow$ DEPARTMENT OF BOTANY $\downarrow$ UNIVERSITY OF WYOMING $\downarrow$ LARAMIE
}

\begin{abstract}
$\downarrow \quad$ INTRODUCTION
Wildfire and bark beetle epidemics are two ecologically important natural disturbances in the Intermountain West, yet we know very little about how these two phenomena interact. It is widely believed that beetle-killed trees increase the risk of severe fires; and trees that are weakened, but not killed by fire, are thought to be more susceptible to beetle invasion. However, few studies have rigorously tested these hypotheses. The GYE is currently experiencing an outbreak of unprecedented intensity and complexity, involving several species of bark beetles, including the mountain pine beetle. The outbreak is affecting multiple species of coniferous trees in and near recently burned areas, providing a timely opportunity to investigate these interactions at multiple scales.
\end{abstract}

In addition to the basic ecological questions posed above, forest managers throughout the western US are grappling with how to deal with the most extensive bark beetle outbreaks ever recorded for the region. Following various kinds of natural disturbance, salvage harvest may be conducted to extract economically valuable timber and/or to reduce perceived risk of subsequent disturbance. However, the consequences of such post-disturbance management on stand structure and function in the context of the current bark beetle outbreaks are largely unknown. There has been some recent attention to salvage harvest in the literature, but empirical studies are relatively scarce. Therefore, as part of this study, we are quantifying the effects of post-beetle salvage logging on fuels, regeneration, and nitrogen cycling in lodgepole pine forests on the Bridger-Teton National Forest.

By means of seven closely related projects (described below), we conducted field work in 2007 in Yellowstone and Grand Teton National Parks, as well as on the Bridger-Teton and Shoshone National Forests, to answer four fundamental questions:

1. What are the current patterns of beetle outbreaks in the Greater Yellowstone Ecosystem, and what factors explain these patterns? [Projects \#1 and \#2]

2. What are the consequences of bark beetle outbreaks and post-beetle salvage harvest on nitrogen dynamics? [Project \#3]

3. How do mountain pine beetle outbreaks influence the risk and severity of wildfire? [Projects \#4 and \#5]

4. Does fire injury in lodgepole pine affect colonization rates, reproductive success, and potential for population increase of mountain pine beetle? [Projects $\# 6$ and \#7] 


\section{Project \#1: Remote Detection of Bark Beetle Damage}

The objective of this research is to map the magnitude, spatial patterns and temporal trend of several concurrent beetle outbreaks including mountain pine beetle, spruce beetle and Douglas-fir beetle. Field work for this project was completed in 2007, and data analysis was conducted in 2008 . The project will be completed in 2009.

Project \#2: Explaining broad-scale infestation patterns of three bark beetle species

The objective of this project is to determine what factors explain bark beetle infestation patterns being mapped at broad scales (project \#1). Field work for this project was completed in 2007, and data analysis was conducted in 2008 . The project will be completed in 2009.

Project \#3: Effects of bark beetle outbreaks and of post-beetle salvage logging on fuel dynamics and nutrient cycling

In 2008, working out of the UW-NPS Research Station, we conducted a second season of presalvage measurements in 10 pairs of mountain pine beetle-attacked lodgepole pine plots in the Green River Lakes area of Bridger Teton NF. Ion-exchange resin methods were used to measure available $\mathrm{N}$ in soils, and temperature/humidity probes were installed. Salvage logging in the treatment plot of each pair has been delayed until summer 2009. After salvage operations are complete, we will return to resample vegetation, fuels, soils, temperature, and humidity and then test for effects of salvage using a before-after-control-impact (BACI) statistical design. Approximately $60 \%$ of lodgepole pine basal area has been killed by the mountain pine beetle in these stands, with no significant differences in beetle activity between control and salvage plots (Fig 1). Soil texture, litter mass, soil N availability, and surface and canopy fuels also show no differences between control and treatment plots prior to salvage. Pre-salvage temperature and humidity data analyses are underway, and the project will continue through 2009.

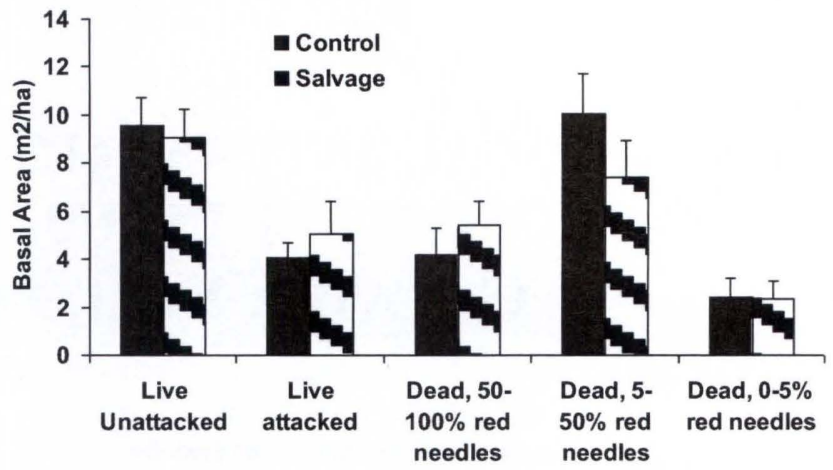

Figure 1. Mountain pine beetle damage in the Green River Lakes area of BTNF. There are no significant differences in beetle damage between control and salvage plots (paired ttest). Error bars are 2SE.

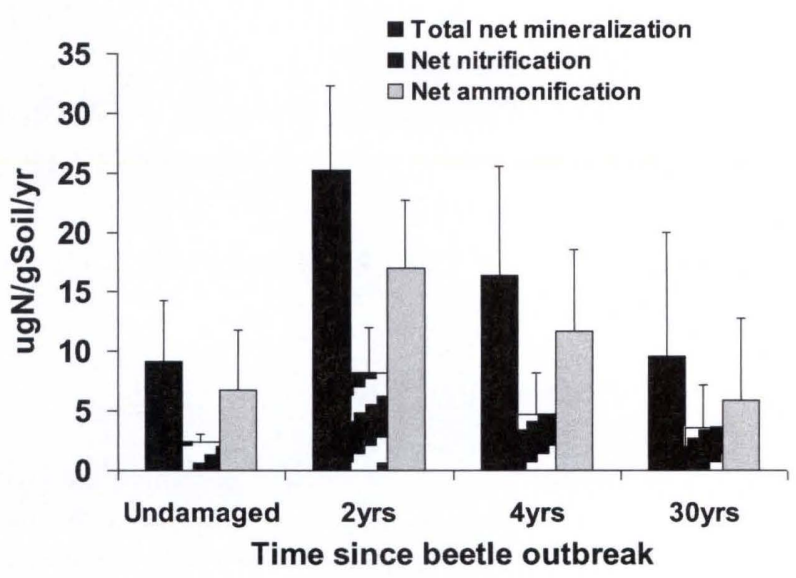

Figure 2. Soil $\mathrm{N}$ transformations following mountain pine beetle outbreak in lodgepole pine. Bars represent the mean of five replicates per class; error bars are 2SE.

\section{Project \#4: Time-since-beetle chronosequence}

The objective of this project is to characterize long-term ( 0 to 30 years after outbreak) effects of mountain pine beetle outbreaks on forest structure and regeneration; surface and canopy fuels; and nitrogen dynamics. In 2008, working out of the UW-NPS Research Station, we completed measurements of soil N transformations along a chronosequence of lodgepole pine forests attacked by mountain pine beetle. The sequence consisted of undamaged, 2-, 4-, and 30-year old beetle outbreaks. Results show a 2.5 fold increase in net nitrogen mineralization 2 years after outbreak (ANOVA $\mathrm{p}=0.04$ ), followed by a declining trend toward undamaged levels 30 years after outbreak (Fig 2). Changes in net ammonification and net nitrification were marginally significant (ANOVA $p=0.07, p=0.10$ respectively). The project will continue through 2009. 
Project \#5: Landscape patterns and the risk of highseverity fire

The objective of this project is to characterize stand structure, regeneration, and the quantity and distribution of surface and canopy fuels in lodgepole pine stands attacked by mountain pine beetle at different times in the past $(2,4,25$, and 35 years ago), as well as undamaged stands. Field sampling was completed in 2007. In 2008 we applied these field data to a suite of fire behavior models (e.g., Behave and Nexus) to evaluate how changes in the fuel complex will likely influence fire behavior under a range of weather conditions. The project will be completed in 2009.

\section{Project \#6: Host preference of MPB}

The objective of this project is to compare mountain pine beetle "performance" (success of attack, growth of larvae, and overall reproductive success) on its two major tree hosts in the Greater Yellowstone
Ecosystem: lodgepole pine and whitebark pine. In 2008, working out of the UW-NPS Research Station, beetle survival and behavior were documented in lodgepole pine and whitebark pine in Yellowstone and Grand Teton National Parks. Data analysis is still underway; the project will be continue through 2009 .

\section{Project \#7: Fire-injured lodgepole pine as a potential reservoir for mountain pine beetle}

The objective of this project is to determine if fire injury in lodgepole pine affects colonization rates, reproductive success, and potential for population increase of mountain beetle. In 2008, working out of the UW-NPS Research Station, lodgepole pine trees of various burn injury classes were sampled for mountain pine beetle and other insects. Background populations of mountain pine beetles were sampled using flight traps, and individual trees were tagged for long-term observation. The project will continue through 2009 . 